IOS Press

\title{
How to use programme theory to evaluate the effectiveness of schemes designed to improve the work environment in small businesses
}

\author{
Kirsten Olsen ${ }^{\mathrm{a}^{*}}$, Stephen Legg ${ }^{\mathrm{a}}$, Peter Hasle ${ }^{\mathrm{b}}$ \\ ${ }^{a}$ Centre for Ergonomics, Occupational Safety and Health, School of Management, Massey University, Palmerston \\ North, Private Bag 11222, New Zealand \\ ${ }^{b}$ National Research Centre for Working Environment, Lersø Parkallé 105, Copenhagen, 2100, Denmark
}

\begin{abstract}
Due to the many constraints that small businesses (SBs) face in meeting legislative requirements, occupational health and safety (OHS) regulatory authorities and other OSH actors have developed programmes which can reach out to SBs and motivate and assist them in improving the work environment. A number of conceptual models help to enhance our understanding of OHS interventions in SBs and their effectiveness. However, they have mainly been evaluated on output rather than the process relating to the change theory underlying the intervention, and hence have seldom been rigorously evaluated. Thus little is known about how particular features of SBs can be taken into account when designing and implementing national programmes. This paper shows how realist analysis and programme theory may be used as a framework for evaluating, developing and improving national intervention programmes for the improvement of the work environment and reducing injuries in SBs. It illustrates this for a specific New Zealand intervention: the Workplace Safety Discount scheme and its implementation in the agriculture sector. In practice, realist analysis should be performed during the planning, implementation and management stages so that ongoing findings can be fed back to the participant social actors to help them make appropriate changes to enhance the likelihood of success.
\end{abstract}

Keywords: SME, OSH, ergonomics, interventions, realist analysis

\section{Introduction}

It is generally accepted that people working in small businesses (SBs) are exposed to serious occupational hazards and that they have a higher injury risk than people working in larger organisations $[5,9$ and 22]. They also lack the resources to control these hazards and have difficulties in meeting legislative demands for control of risks [12 and 27]. In comparison with larger businesses, SBs are usually characterised as having insufficient financial and managerial resources. This characteristic has been a focal point in business research literature for many years [ 4 and 24]. In particular, the SB owner is often the manager and has to deal with a number of different administrative and management functions, such as sales, planning, human resources, finance, accounting and billing important to their core business. In addition the owner-managers have to be aware of their occupational safety and health (OSH) duties, which - in their view - are not relevant to their core business and not of high priority. OSH research in SBs has to a large extent focused on high-risk activities and insufficient compliance with health and safety regulations [3, 10 and 19] and provided broad support for the idea that inadequate knowledge and resource constraints are the main explanations for the problems faced by SBs [12].

Due to the many constraints that SBs face in meeting legislative requirements, OSH regulatory authorities and other OSH actors have pursued the development of programmes which can reach out to SBs and motivate and assist them in improving the work environment. Not only has research provided some know-

\footnotetext{
Corresponding author. E-mail: k.b.olsen@massey.ac.nz
} 
ledge about the nature of the special risks associated with SBs and of the possibilities for intervention, but a number of conceptual models have been developed that may help to enhance our understanding of $\mathrm{OSH}$ interventions in SBs and their effectiveness [11, 12 and 14]. Such models tend to recommend the development of industry-specific interventions with a focus on the SBs' specific external intermediaries and internal cultures, as well as their needs, internal resources and processes. However, these models have not been rigorously evaluated by empirical research and there is scant knowledge about how particular features of SBs can be transformed into national programmes, which in turn can successfully prevent work-related injuries, accidents and diseases.

There is a twofold problem for regulators and other actors in the case of prevention of occupational risks in SBs. First, there is a problem in reaching out to this group due to its size and nature. The large number of SBs, their inadequate managerial resources and their informal nature make them difficult and expensive to reach with the intervention and also to evaluate. Second, there is a problem of actually convincing employers and employees that it is necessary and beneficial for the business to do something to control risks.

There are only a few examples of scientific evaluations of national programmes aimed at SBs and they mainly describe pilot interventions or programmes $[6$, 15,16 and 23]. These programmes are mainly evaluated on the output and not the process in relation to the change theory behind the intervention or programme. There are two reasons for this; firstly the change theory- the theory about the mechanisms that make the programme work - are often not explicitly expressed [28]; and secondly it is often difficult to identify clear causal relations in complex intervention programmes [13 and 18].

However, in spite of the constraints there is an emergent need to understand how programmes can be designed and implemented in such a way that they can create a positive effect and, subsequently, how to follow the progress of the programme and make the necessary alterations in order to ensure that they can still achieve the main objectives.

The purpose of the present paper, therefore, is to assist in the development of a process that may help in understanding the fundamental drivers underlying various programmes. In particular, it probes the issue of transforming OSH knowledge into real-life national programmes which have the potential to influence the behaviour of SBs. We believe that it is possible to take an important step in this direction by applying 'programme theory' $[7,21]$ and 'realist analysis' to the field of OSH and SBs. Realist theory is concerned with theories of change- the fundamental rationale and driver(s) underlying what makes a programme work [20]. It has been used in the evaluation of public programmes in local communities, education, healthcare and similar fields.

This paper gives an introduction to realist analysis and programme theory as a framework for evaluating, developing and improving national intervention programmes for the improvement of the work environment in SBs. It illustrates how realist analysis can be applied using a specific New Zealand intervention: the Workplace Safety Discount (WSD) scheme and particularly its implementation in the agriculture sector - as an example.

\section{A theoretical framework for the analysis of national programmes aimed at small businesses}

Realist analysis aims at evaluating intervention programmes in relation to the entire programme including the design, implementation, management and outcome. It attempts to cut through the complexity by focusing on the theories underlying the social intervention: the programme theory. It attempts to explain the underlying mechanisms by which any programme is expected to work and the contextual constraints which can hamper its delivery, success and effects [7 and 20]. The central question is: what works, for whom, in what circumstances, in what respect and how [20]? In principle, a programme is built on a logical sequence of inputs, activities, outputs and subsequently short- and long- term effects. It is implemented in a specific context that influences the social actors who are supposed to carry out the changes and which will determine to what extent activities and outputs will be achieved. The originators (e.g. the governmental work environment inspectorate) of the programme provide the input necessary to undertake the activities which are often handed over to intermediaries to disseminate to the users (in this case the SBs) which in turn creates the output. This is illustrated in figure 1 . However, in order to get this logical sequence to work there must be a mechanism which makes it work. It can be called a theory of change or 'programme theory'. Essentially, programme theory provides the fundamental rationale and the underlying driver(s) that makes a programme work. In general there are three basic types of mechanisms [26]: 
- Information provision (sharing information and argumentation)

- Incentives (economic and image promoting)

- Punishment (demands, controls and sanctions)

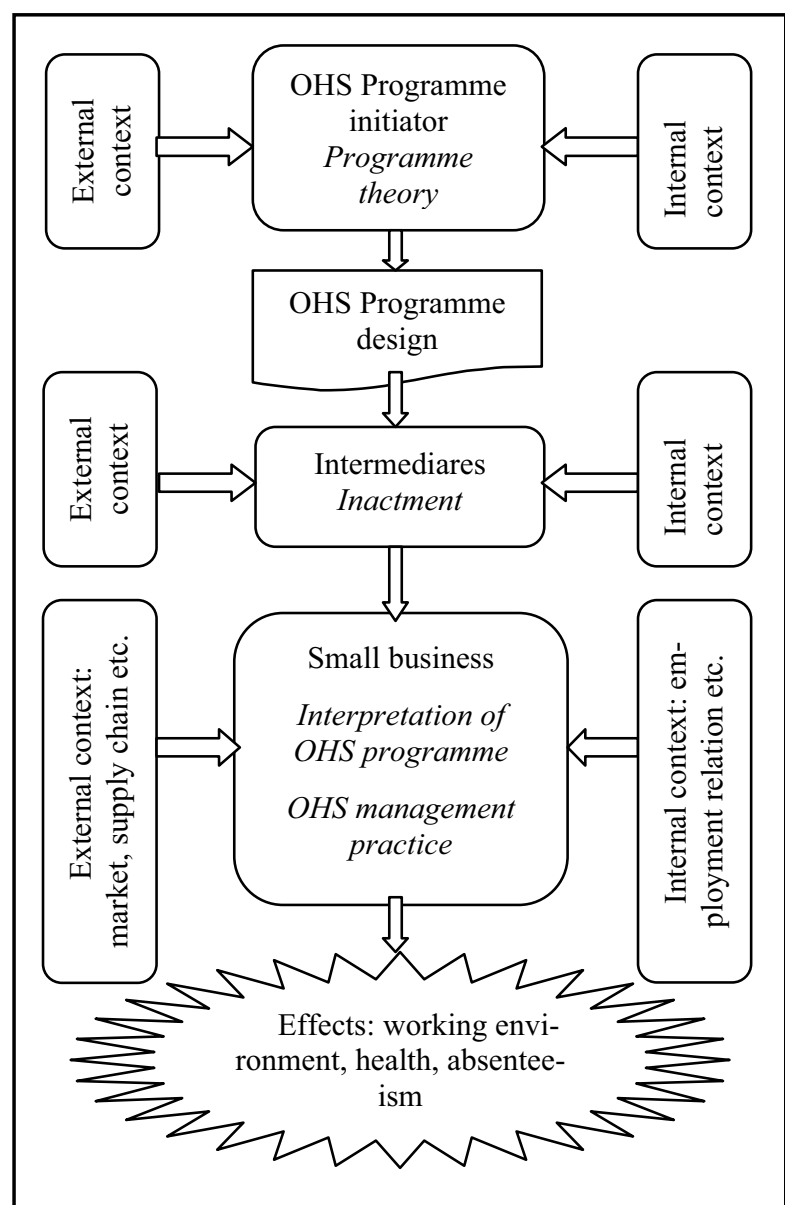

Figure 1 Schematic simple model of the programme theory chain inspired by Pawson [19]

A simple example of 'programme theory' in SBs could be: If a) SB owner-managers are informed about the risk of hearing impairment when noise exposure is $85 \mathrm{~dB}(\mathrm{~A})$ or above and that it can be prevented by using hearing protection, then $b$ ) hearing protectors will be used by employees when noise exceeds $85 \mathrm{~dB}(\mathrm{~A})$. The question is whether this is actually valid. It is therefore necessary to add followup questions, such as:

- Once both parties have been informed about noise, why should SB owner-managers encourage employees to wear hearing protectors?
- What is the mechanism that would make the employees wear hearing protectors after being encouraged by the owner-manager?

The programme theory should therefore be extended as follows: owner-managers and the employees want to avoid impaired hearing and they do not want to signal to other parties that they do not care for their hearing and therefore they use hearing protectors.

The examples above constitute causal drivers. But even if they work, there can be contextual moderators, which are variables influencing whether, and to what extent, the causal effect will happen. Using the hearing impairment example above, if SB ownermanagers are informed in writing and they do not read the material (perhaps because they are too busy and do not prioritise OSH), then hearing protectors will not be used. Whether SB owner-managers actually read written material is, therefore, a strong contextual moderator. It is also an example of a possible implementation failure: the SB owner-managers do not read written material, therefore they are not informed about the risk of hearing impairment and do not take action. The implementation strategy of providing written information material has failed. Moreover, if the SB owner-managers have actually read the material and are considered to be informed, and if they do not take action by encouraging employees to wear hearing protectors, and hence the employees do not use them, this constitutes a programme theory failure. As illustrated by the above simple example, the constructs of programme theory and contextual moderators can be helpful in the design and evaluation of SB programmes to improve the work environment.

The logic in the model is that the OSH actors have identified a need to intervene in SBs and that they design an intervention programme based on a programme theory about how the need can be fulfilled. The programme theory will contain a theory about how it can reach the SB target group and how it can influence them to do as intended and, finally, that the intended action will have positive effects on the control of risk. There are, in particular, three points with important moderators which can enhance or constrain the effects of the programme theory. The first is 'contact with the SB': are they actually reached? The second is 'interpretation in the SB': do they actually interpret the programme and act as intended? The third is 'the effect'; that is whether the action leads to the intended outcome? 
In the literature, a number of moderators are described - most often as constraints. These need be taken into consideration in the design and evaluation of SB programmes. Based on reviews of the literature[12,15,16 and 19] some of the most common moderators are:

\section{Contact with SBs}

- SBs do not actively search for information about OSH

- SBs rarely read material mailed to them

- The large number of SBs makes it expensive to reach out to the majority of them in a personal way

- Inadequate resources in terms of attention and time for contact

- SBs tend to react to ad hoc needs

- Dependence on personalised contact and on suppliers

\section{Interpretation of programmes}

- Limited trust in authorities (SBs think the authorities do not understand the special needs of SBs and that they are responsible for creating too much bureaucracy)

- An underestimation of risk

- An overestimation of their own knowledge and capability

\section{Change process}

- Limited funds to invest in $\mathrm{OSH}$

- A lack of attention and time to implement actions

- Inadequate capability to carry out actions as intended

- A lack of knowledge about available solutions

Some of the more common positive moderators include: SB managers know their own production processes and may have a firm practical grasp of what the OSH risks are and thus find simple solutions more easily, and SB managers work close to, or with, their workers and therefore more readily accept ethical motives not to injure them. In addition to these SB moderators, there will also be more contextual moderators, such as the:

- economic situation

- availability of labour

- stability of the political situation

- power relations between employers and employees.

Such moderators will have a potentially strong influence on any programme, but it is not possible to generalise their effect.

\section{Applying realist analysis to the New Zealand Workplace Safety Discount (WSD) scheme}

One example of a national intervention programme targeting small business is the New Zealand WSD scheme developed by the New Zealand Accident Compensation Corporation (ACC) (a crown institution that provides no-fault personal injury cover for all New Zealand residents including work-related injuries) and the Department of Labour (DoL). The scheme is an incentive scheme that offers SBs 10\% reduction in their insurance levy if they fulfill certain requirements. The WSD scheme was introduced on 1 April 2006 and applies to SBs with fewer than 10 employees, as well as self-employed people in specific subsectors of certain industries, including agriculture, forestry, construction, road freight, motor trades and inshore fishing.

\subsection{Background for the WSD scheme}

The background for the WSD is the introduction of the Workplace Safety Management Practice (WSMP) programme by ACC in 2001. This is an incentive programme involving a voluntary OHS management system audit mainly targeting medium to large business. Depending on how well developed the management system is the business can achieve primary, secondary and tertiary level accreditation and achieve $10 \%, 15 \%$ or $20 \%$ reduction in insurance levy respectively. However, very few SBs applied for the WSMP, which was perceived to be due to the requirements of formal and documented OHS management systems. DoL and ACC wanted to develop a similar incentive scheme for SBs in high risk industry sectors. They perceived that SBs had a higher incident rate and higher cost of ACC claims compared to medium and large businesses and believed that this was due to the owner-managers' lower levels of health and safety awareness and general hazard management practices. The aim of the WSD scheme is for SBs in high-risk sectors to reduce the number and severity of injuries and diseases, and to make ongoing improvements in OSH management capability and practice.

\subsection{An overview of the WSD scheme}

SBs in the specified high risk industry sectors can apply for a 10 per cent discount off its ACC levy after it fulfils three requirements: 1) they have to demonstrate experience or training in common haz- 
ard in the industry and hazard management, 2) they have to be able to satisfactorily fill in a self assessment form, and 3) They have to accept an audit by an independent auditor (15\% of the applicants are audited).

The first requirement can be fulfilled by attending two half-day training courses developed by the ACC in cooperation with the industry associations. The training courses are free, delivered locally by approved industry training organisations and developed in co-operation with ACC and the industry associations. The self-assessment was developed in cooperation between DoL, ACC and the industry associations. The auditors are trained by approved ACC trainers. SBs are selected for audits if their selfassessment is unsatisfactory and in addition a proportion is randomly selected for audits by ACC employees in the insurance product department. The WSD are promoted primarily by the industry training organisations and secondarily on ACC's web-page. The general scheme design is shown in figure 2.

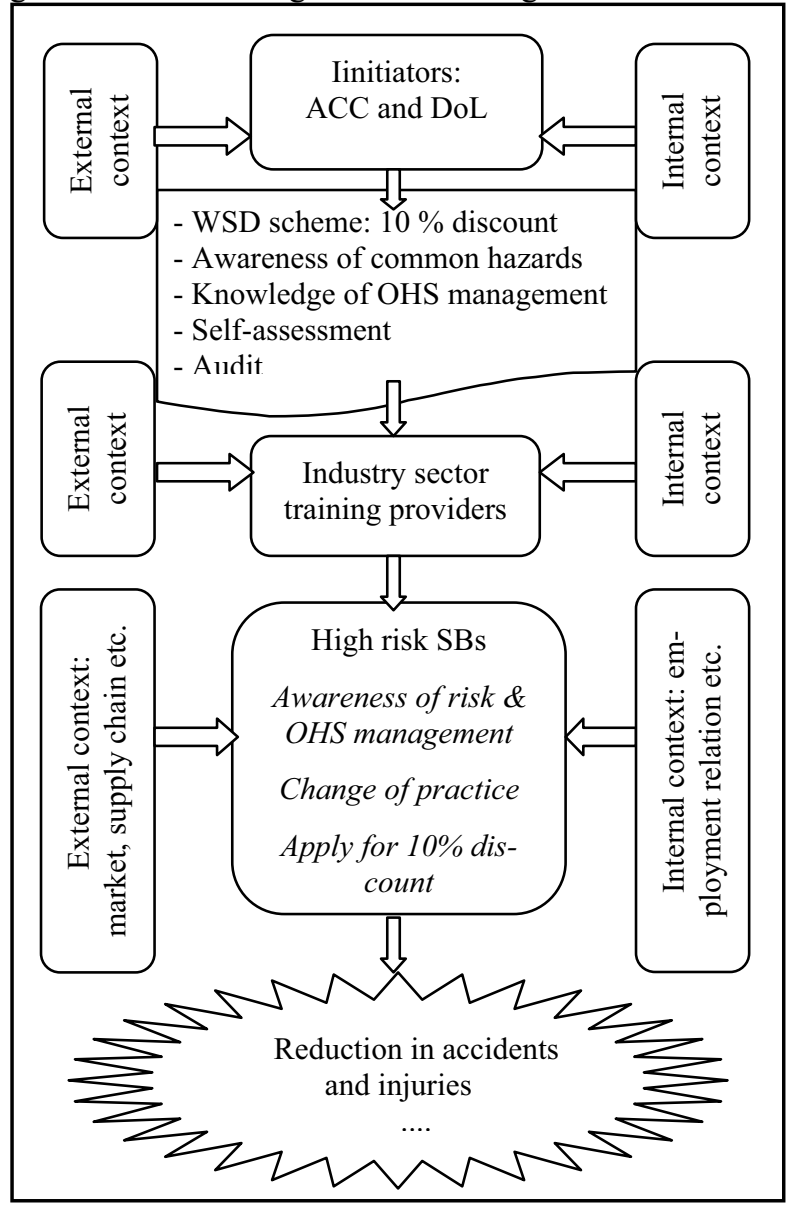

Figure 2 General model of the WSD scheme

\subsection{The 'programme theory' behind the general WSD scheme}

In order to use realist analysis and identify the programme theory behind the WSD in practical terms for this study, it was necessary to ask Pawson's [20] central questions in a more specific manner as follows:

- Why should it work to promote WSD through industry training organisations? For whom should it work, in what situations?

- Why should courses work, for whom and in which situations?

- Why should the self-assessments work, for whom and in which situations?

- Why should the audits work, for whom and in which situations?

- Why should the incentive (10\% levy discount) work, for whom and in which situations?

Firstly the WSD scheme was based on the need for intervention to reduce severe injuries and disease in the chosen high risk industries.

The main driver was an economic incentive: a $10 \%$ reduction in the ACC levy based on a programme theory that SBs in the high risk sectors saw the ACC levy as a burden [8]. The input was:

- information to the small businesses through industry associations and local training organisations about the scheme based on the programme theory that SBs prefers personalized contact by somebody they trust (information mechanism),

- two free half-day training courses (information mechanism) delivered locally to improve knowledge about specific hazards and OSH management. The programme theory behind this feature was SBs have limited economic resources (thus no course fees (reward mechanism)) and limited time (thus courses delivered locally and only lasting half a day).

The drivers for putting the knowledge gained into practice were a perception that SBs owner-managers have a positive attitude towards the work environment and want to be good employers and that a possible control of their self-assessment through an audit would enforce it (punishment mechanism). Re-audit was in this case required to maintain the reduction and result in ongoing improvements in OHS management.

The last part of the programme theory is that improved OHS management will result in improved work environment and reduce the numbers of severe injuries and diseases [8]. 
Some internal context moderators were taken into account: insufficient time and financial resources, and the preference for informal management with little and simple written documentation.

External context moderators were also taken into account. The first contact with the SB was to be conducted by the industry associations and the industry training organisations. The use of the industry sector network was intended to mitigate the fact that SBs are numerous and not formally networked and therefore difficult to reach using standard methods often used. The WSD was also promoted through trade magazines, expos, safety adviser visits and ACC's materials that could be downloaded from its website.

Despite these efforts, ACC reported in 2008 (two years after the launch of the scheme) that uptake was lower than expected due to the fact that it was merely included on its website, and not actively promoted [1]. In 2011 3,357 SBs had joined the scheme. This was around a third of what ACC predicted the uptake would be in 2009 - 9,300 SBs [8 and 25]. The ACC has not been able to measure the effects on the SBs in terms of a reduction in their injury claims rates in NZ as a whole. However, it has reported that there has been a reduction in the number of injuries among SBs that participated in the scheme [2] but has not presented any evidence to support that statement.

In a small study of seven SBs in the high risk industries covered by the WSD [15] it was found that the contact mechanism and the interpretation of the WSD scheme seemed to work. The economic driver worked for some but not for others. The mechanism (making change in the company) was affected by the owner's perception of good practice (which may or may not be correct) as a moderating factor, while the uptake of the scheme was affected by a lack of time to attend training courses or apply for the discount. There was also a perception that the audit was complicated and contained too many documents.

\subsection{The WSD scheme implemented in the agriculture sector}

One of the important points in a realist analysis [20] is the fact that intervention programmes are embedded in social systems, and they are changed through the participants' activities and engagement as well as influenced by other programmes and events. They are therefore to be understood as open systems which cannot be controlled by the programme initiators. An analysis of the development of the WSD scheme in the agriculture sector exempli- fies how intervention programmes change as local actors become involved.

The ACC agriculture management team and the industry association (Federated Farmers) decided to deliver the approved courses through FarmSafe using two of their already-developed training courses: 'FarmSafe awareness' (half-day) and 'FarmSafe plans' (one day), both subsidized by the Tertiary Education Commission. The underlying programme theory for choosing FarmSafe was that an evaluation of the training courses concluded that they reached out to small farmers (the evaluation assessed the attendance of the courses but not if any changes had been implemented) [17]. Here we have the first amendment of the WSD scheme: the half-day course was substituted by a one-day course. We also find the influence of another system i.e. the Tertiary Education system and funding from this system manage by The Tertiary Education Commission (TEC). In 2011 TEC changed it funding of industry courses from funding of individual courses to funding of qualifications which means that only coursed that are included in qualifications receive funding. The FarmSafe plans course is only an optional course in the different farming qualifications. This means that the farmer now have to pass the other courses in a qualification before the funding is activated. Thus it is less affordable for FarmSafe to offer the FarmSafe plans course. FarmSafe does not employ trainers per se. Rather, it engages contract trainers that are based locally throughout New Zealand. It mainly relies on these local contract trainers to make the contact to the farmers. These trainers are independent consultants and are only partially dependent on the amount of FarmSafe training courses in their region and have to base their livelihood on other consultancies. The change in funding from TEC means that the FarmSafe plans course has a lower priority from FarmSafe and is not promoted by the trainers. Some trainers tried to maintain their income by delivering the WDS half-day workshop on OHS management which will be funded at a lower rate when the farmer applies for the WSD discount. Whether this will increase or diminish the numbers of farmers that will attend the workshop and apply for the WSD discount has yet to be realized. This is another example of the open system being influenced by other systems. The implementation of the WSD scheme in the Agriculture sector is illustrated in figure 3. Examples of internal (to the right) and external (to the left) factors influencing the social actors in the open system are illustrated. As described earlier, the basic change 


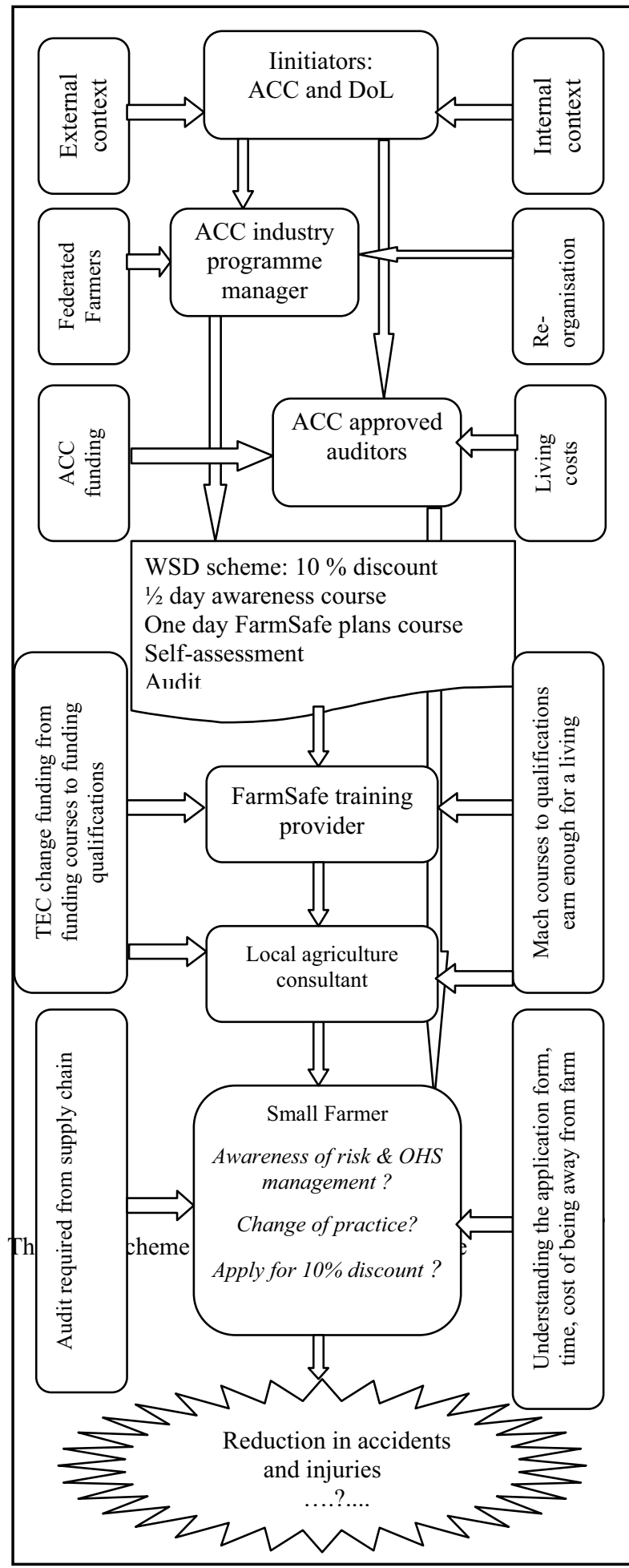

mechanism (programme theory) that the creators based the scheme on was mainly the economic benefit (incentive mechanism) and information provision (argumentation) and lastly the random audit (punishment mechanism). Since the scheme is part of an open system it becomes important to analyse if or how the intervention programme is twisted through the implementation and management of the scheme (e.g. from half day to one day courses) and how it amalgamates with other programmes during the course of practical implementation such as the integration with already existing training activities and in the trainers contact to the farmers.

Through interviews (carried out by the first author, Leigh-Ann Harris and Kristina Gunnarsson, April 2011) with three FarmSafe trainers it was discovered that the strategy for recruiting farmers to the one-day 'FarmSafe plans' course and encouraging them to apply for the discount built on arguments like:

- The other farmers in your area are subscribed to the planned course, you should come and catch up with them on the course (mechanism: social benefit)

- I have implemented the FarmSafe plans myself and my farm runs much more efficient (mechanism: economic benefit)

- If you are in the WSD scheme it is much more likely that an inspector from Department of Labour will assess that you have taken all practical steps to provide a safe workplace in the case of an investigation (punishment mechanism)

In the trainers' promotion of the WSD scheme the punishment mechanism (persecution) was more prominent and the economic incentive mechanism was changed from focusing on the discount to focusing on productivity.

\section{Conclusion}

This paper has exemplified how realist analysis and programme theory may be used in practice to identify the underlying theory and the mechanism behind an intervention programme. It shows how it can be used in a subsequent evaluation of a national scheme designed to improve the work environment in small businesses to assess its effectiveness and how it works. In this way it is possible to identify whether a lack of effects of a programme is due to a failure in the programme theory or an implementation failure. This kind of knowledge is necessary in order to make adaptations to programmes during implementation and management in order to increase their efficacy. 
The example in this paper (the WSD in agriculture in New Zealand) shows that the programme theory was modified by the social actors (FarmSafe and contract trainers) involved and influenced by other interacting schemes and contextual factors (changes in funding). Our findings suggest that realist analysis is a promising methodology to evaluate national programmes or schemes that are designed or aimed at improving the work environment and reducing injuries in small business. However in practical application, realist analysis should be performed during the planning, implementation and management stages of the programmes/schemes, so that ongoing findings can be fed back to the participating social actors so that they can make changes as appropriate in order to enhance the likelihood of success.

Finally, realist analysis has a much wider scope. It could also be beneficially used to evaluate broader work environment programmes.

\section{References}

[1] Accident Compensation Corporation. (2008). Annual Report 2008 (annual report). Wellington: Accident Compensation Corporation.

[2] Accident Compensation Corporation. (2009). Annual Report 2009. Wellington: Accident Compensation Corporation, New Zealand.

[3] Baldock, R., James, P., Smallbone, D., \& Vickers, I. (2006). Influences on small-firm compliance-related behaviour: the case of workplace health and safety. Environment and Planning C-Government and Policy, 24(6), 827-846.

[4] Beaver, G. (2003). Management and the small firm. Strategic Change, 12 (2), 63-68.

[5] Champoux, D., \& Brun, J. P. (2003). Occupational health and safety management in small size enterprises: an overview of the situation and avenues for intervention and research. Safety Science, 41(4), 301-318.

[6] Curtis Breslin, F., Kyle, N., Bigelow, P., Irvin, E., Morassaei, S., MacEachen, E., et al. (2010). Effectiveness of Health and Safety in Small Enterprises: A Systematic Review of Quantitative Evaluations of Interventions. Journal of Occupational Rehabilitation, 20(2), 163-179.

[7] Dahler-Larsen, P. (2001). From Programme Theory to Constructivism: On Tragic, Magic and Competing Programmes. Evaluation, 7(3), 331-349.

[8] Department of Labour. (2006). Regulatory impact statement for proposed workplace safety ACC levy discount for small businesses in six high risk industries. Retrieved 24/03/2010. from http://www.osh.govt.nz/publications/research/acclevy0603/pg1.html.

[9] Fabiano, B., Curro, F., \& Pastorino, R. (2004). A study of the relationship between occupational injuries and firm size and type in the Italian industry. Safety Science, 42(7), 587-600.

[10]Fairman, R., \& Yapp, C. (2005). Enforced Self-Regulation, Prescription, and Conceptions of Compliance within Small Businesses: The Impact of Enforcement. Law \& Policy, 27(4), 491-519.
[11]Frick, K., Nichols, T., \& Walters, D. (2009). Health and Safety Representation in Small Firms: a Swedish success that is threatened by political and labour market changes. In Workplace Health and Safety - International Perspectives on Worker Representation: Palgrave Macmillan.

[12] Hasle, P., \& Limborg, H. J. (2006). A review of the literature on preventive occupational health and safety activities in small enterprises. Industrial Health, 44(1), 6-12.

[13] Kristensen, T. S. (2005). Intervention studies in occupational epidemiology. Occupational and Environmental Medicine, 62, 6.

[14] LaMontagne, A., Stoddard, A., Roelofs, C., Sembajwe, G., Sapp, A., \& Sorensen, G. (2009). A hazardous substance exposure prevention rating method for intervention needs assessment and effectiveness evaluation: the Small Business Exposure Index (Vol. 8, pp. 10).

[15]Legg, S., Olsen, K., Lamm, F., Laird, I., Harris, L.-A., \& Hasle, P. (2010). Understanding the programme theories underlying national strategies to improve the working environment in small businesses. Policy and Practice in Health and Safety, 8(2), 5-35.

[16] MacEachen, E., Kosny, A., Scott-Dixon, K., Facey, M., Chambers, L., Breslin, C., et al. (2010). Workplace Health Understandings and Processes in Small Businesses: A Systematic Review of the Qualitative Literature. Journal of Occupational Rehabilitation, 20(2), 180-198.

[17] Morgaine, K., Langley, J. D., \& McGee, R. O. (2006). The FarmSafe programme in New Zealand process evaluation of year one (2003). Safety Science, 44, 12.

[18] Neumann, W. P., Eklund, J., Hansson, B., \& Lindbeck, L. (2010). Effect assessment in work environment interventions: A methodological reflection. Ergonomics, 53(1), 130-137.

[19]Olsen, K., Harris, L.-A., Laird, I., Legg, S., Perry, M., \& Hasle, P. (2010). Differential intervention strategies to improve the management of hazardous chemicals in small enterprises. Policy and Practice in Health and Safety, 8(2), 57-76.

[20]Pawson, R. (2006). Evidence-based policy. A realist perspective (first ed.). London: SAGE Publications Ltd.

[21]Rogers, P. J. (2008). Using programme theory to evaluate complicated and complex aspects of interventions. Evaluation, 14(1), 29-48.

[22] Sørensen, O. H., Hasle, P., \& Bach, E. (2007). Working in small enterprises - Is there a special risk? Safety Science, 45(10), 1044-1059.

[23] Stave, C., Pousette, A., \& Törner, M. (2008). Risk and safety communication in small enterprises - how to support a lasting change towards work safety priority. Journal of Risk Research, $11(1 / 2), 195-206$

[24] Storey, D. J. (1994). Understanding the small business sector. London: Routledge.

[25] Teng, S. (2011). ACC responses to data question raised by Centre for Ergonomics Occupational Safety and Health researcher Dr. Kirsten Bendix Olsen. Accident Compensation corporation, New Zealand.

[26] Vedung, E. (1997). Public policy and program evaluation. New Brunswick: Transaction Publishers.

[27] Vickers, I., James, P., Smallbone, D., and Baldock, R. (2005). Understanding small firm responses to regulation: The case of workplace health and safety. Policy Studies, 26(2), 149-169.

[28] Wijk, K., \& Mathiassen,SE, M. (2011). Explicit and implicit theories of change when designing and implementing preventive ergonomics interventions - a systematic literature review. Scandinavian Journal of Work Environment and Health, 37(5), 13. 